\title{
Bacterial Transfer from Hands While Eating Popcorn
}

\author{
Kimberly A. Baker1, Inyee Y. Han1, J. Bailey1, Lauren Johnson1, Edward Jones', \\ Amy Knight', Mollye MacNaughton', Peter Marvin', Katherine Nolan1, \\ Rose Martinez-Dawson ${ }^{2}$, Paul L. Dawson ${ }^{1 *}$ \\ ${ }^{1}$ Department of Food, Nutrition and Packaging Sciences, Clemson University, Clemson, SC, USA \\ ${ }^{2}$ Department of Mathematical Sciences, Clemson University, Clemson, SC, USA \\ Email: "pdawson@clemson.edu
}

Received 7 September 2015; accepted 7 November 2015; published 10 November 2015

Copyright (C) 2015 by authors and Scientific Research Publishing Inc.

This work is licensed under the Creative Commons Attribution International License (CC BY). http://creativecommons.org/licenses/by/4.0/

(c) (i) Open Access

\begin{abstract}
Popcorn is a very social food, often shared with others and offered at many major sporting events, concerts, movies, and fairs. However, sharing may not be safe since microorganisms found on hands may be transferred onto the shared popcorn. This study was conducted to determine if bacteria are transferred from hands to popcorn during handling. Over 30 samplings revealed that bacterial transfer to popcorn from hands was very low; however transfer did occur with large variation between subjects. Since hands and surfaces can carry bacteria in situations where food is being shared, transferring bacteria from one person to another person is always a risk.
\end{abstract}

\section{Keywords}

\section{Component, Popcorn, Bacterial Transfer, Food Safety, Sharing Food}

\section{Introduction}

Whether attending a sporting event, circus, or movie, popcorn is a staple food at nearly all entertainment events in the United States. Based on archeological evidence, popcorn originated in the Americas (most likely South America) and was spread from the New World to the rest of the World. In the 1820s, popcorn started to make its appearance in the US on city streets, stadiums, fairs, and even railroad stations possibly being brought back by sailors from the Chilean seaport of Valparaiso. During the Great Depression of the 1930s, popcorn's popularity erupted when movie owners realized that they could sell the snack at a low price with a high profit [1]. By the 1950s, movie theater popcorn had become a huge business throughout all of America. The evolution of the

\footnotetext{
${ }^{*}$ Corresponding author.
}

How to cite this paper: Baker, K.A., Han, I.Y., Bailey, J., Johnson, L., Jones, E., Knight, A., MacNaughton, M., Marvin, P., Nolan, K., Martinez-Dawson, R. and Dawson, P.L. (2015) Bacterial Transfer from Hands While Eating Popcorn. Food and Nutrition Sciences, 6, 1333-1338. http://dx.doi.org/10.4236/fns.2015.615139 
snack's popularity increased from then on with the creation of Jiffy Pop ${ }^{\mathrm{TM}}$ stove-top popcorn cooking product and the invention of the microwave, which used popcorn as its first ever experimentally cooked food.

Popcorn is not a food normally associated with bacteria and foodborne illness; however, Anaya et al. (2006) [2] reported that Salmonella ssp. survived microwave cooking when inoculated at concentrations of $9 \times 10^{4}$ CFU/g or greater. Thus the potential exists for survival and cross contamination of cooked popcorn. The microflora residing on human skin is diverse (Gao et al., 2007; Grice et al., 2008) [3] [4] with considerable variation among individuals. Fierer et al. (2008) [5] examined the hands of 51 young adults and identified more than 150 unique species of bacteria and 4742 different phylotypes from the hands sampled. The most abundant bacterial genera and those found on nearly all hands were Proprionibacterium, Streptococcus, Staphylococcus, Corynebacterium and Lactobacillus. While these general classifications of bacteria were found on most hands, significant individual variation existed with even pairs of hands sharing only $13 \%$ of their phylotypes. These researchers also reported significant differences of microbial flora between dominant and non-dominant hands and also between men and women. Women exhibited greater microbial diversity than men, possibly in part since men generally have more acidic hands than women.

Popcorn is a snack often times consumed by more than one individual and is a food routinely shared by a group of friends or family. While individual serving packages are available, most popcorn servings are large enough for more than one person. When eating popcorn someone will likely put their hand in and out of the bowl or container several times before the whole package is completely consumed and the container is often shared until hands of several people have been placed inside the bowl multiple times. Hands play a major role in the transmission of infection in healthcare, food industry, community and domestic settings (Jumaa, 2005) [6]. Jumaa (2005) [6] illustrated the importance of hand hygiene on disease transmission by using the keyword "handwashing" to search the PubMed system and finding 187 citations published from 1968 to 1983 while 1535 were reported from 1990 to 2003. A more recent search of the literature by the past three decades found that 932, 3538 and 5463 journal articles using handwashing as a keyword were published from 1984 to 1994, 1994 to 2004 and 2004 to 2014, respectively. There are numerous studies examining handwashing and bacteria residing on the hands of healthcare workers $(1,160,000$ research citations in Google Scholar using handwashing and health care as keywords). As a survey of the general public, Judah et al. (2010) [7] examined the hands of commuters in five UK cities and reported that $28 \%$ carried bacteria of fecal origin. Interestingly, in this same study, bus commuters had higher fecal bacteria counts than train riders. Although most of these species are harmless, there is still potential to become ill from ingesting unwanted pathogenic microorganisms that are transferred from cross-contamination of foods such as popcorn. Environmental surfaces can also harbor bacteria that can be transferred to skin. From 1999-2003, Reynolds et al. (2005) [8] monitored the hygiene of 1061 surfaces that included stores, daycares, offices, gymnasiums, airports, movie theaters and restaurants in four US cities (Chicago, Tucson, San Francisco and Tampa). Surfaces were tested for biochemical markers of blood (hemoglobin), mucus (amylase) and urine/sweat (urea) as well as (general hygiene) protein, total coliforms and fecal bacteria. For all surfaces tested, 1 in 4 were judged to be heavily soiled ( $>200$ ug protein $/ 10 \mathrm{~cm}^{2}$ ) while 1 in 5 tested positive for at least 1 biochemical marker. Surfaces categorized as miscellaneous activities, which included movie theaters and restaurants, were found to have $21 \%$ and $51 \%$ of samples positive for biochemical markers and highly contaminated, respectively. Thus the current study was devised to determine the number of bacteria transferred to popcorn from hands during consumption. The specific objectives of this study were to: determine the amount of bacteria (non-pathogenic Escherichia coli) transferred from a human hand to 1) a handful of popcorn taken from a bowl and 2) popcorn remaining in the bowl after removing one handful.

\section{Methods}

\subsection{Bacterial Inoculum}

An Escherichia coli ampicillin-resistant strain with a fluorescent gene was used for the bacterial transfer and survival studies. A non-pathogenic E. coli strain JM109 was labeled with jellyfish green fluorescent protein according to the following protocol as described previously (Jiang et al., 2002) [9]. The competent bacterial cells were electroporated in a Gene Pulser II (Bio-Rad) with plasmid vector pGFPuv (ClonTech, Palo Alto, CA). Transformants were selected from isolated colonies grown on Luria-Bertani agar (LB) plates containing $100 \mathrm{~g}$ ampicillin/mL. The resulting ampicillin-resistant transformants emitted bright green fluorescence under UV light. The stability of GFP label in the E. coli strain was determined by streaking on trypticase soy agar (TSA) 
plates containing $100 \mathrm{~g}$ ampicillin/mL for several generations. The E. coli $\mathrm{JM} 109$ culture was held in a $-80^{\circ} \mathrm{C}$ freezer in vials containing tryptic soy broth (Becto ${ }^{\mathrm{TM}}$ Tryptic Soy Broth, Becton Dickinson and company Sparks, MD, USA) supplemented with $20 \%$ (v/v) glycerol (Sigma, St. Louis, MO, USA). The frozen vial was thawed at room temperature prior to culturing. From this thawed vial, $0.1 \mathrm{~mL}$ of culture was transferred to $10 \mathrm{~mL}$ TSB (DIFCO) containing 0.5\% ampicillin (Sigma, St. Louis, MO, USA) in 2 loosely screw-capped tubes and then the tubes were incubated for $16-18 \mathrm{~h}$ at $37^{\circ} \mathrm{C}$ with vigorous shaking (Thermolyne Maxi-Mix III type 65,800, Barnstead/Thermolyne, Dubuque, IA). The second transfer was prepared from this first transfer culture by adding $0.1 \mathrm{~mL}$ from the first transfer tube to another fresh $10 \mathrm{~mL}$ TSB (DIFCO) with $0.5 \%$ ampicillin (Sigma), and again incubated for $16-18 \mathrm{~h}$ at $37^{\circ} \mathrm{C}$ with shaking. After incubation, the cells were harvested by centrifugation at 3000 rpm (1200 g) (IEC HN-SII Centrifuge, International Equipment CO., Inc., Needham Heights, MA, USA), then the pellet resuspended in $10 \mathrm{~mL}$ of sterile peptone solution (0.1\%) (Bacto peptone, Becton Dickinson) to obtain a population of approximately $6-7 \log \mathrm{CFU} / \mathrm{mL}$. Initial cell populations were verified by enumeration of the cells following surface plating in TSA containing 0.5\% ampicillin (DIFCO ${ }^{\mathrm{TM}}$ Tryptic Soy Agar, Becton Dickinson and company Sparks, MD, USA) and incubating at $37^{\circ} \mathrm{C}$ for $24 \mathrm{~h}$.

\subsection{Experimental Treatments}

Orville Redenbacher's Naturals, Simply Salted Microwave Popcorn ${ }^{\mathrm{TM}}$ was used for this study which was believed to be representative of popcorn consumed without high levels of salt and butter. Control samples were inoculated to ensure that salt levels in the rinse solution used to recover bacteria did not inhibit the growth of $E$. coli. Tryptic soy agar plates with ampicillin were labeled with the date, dilution, and sample name. Treatments included: 1) inoculated hand, 2) control popcorn sample removed with sterile gloved hands, 3) control popcorn sample remaining in the bowl and removal of a handful with sterile gloved hands, 4) popcorn sample removed with inoculated hands and 5) popcorn remaining in the bowl after removal of a handful with an inoculated hand. For treatment 1, each subject washed their hands with warm water and soap, allowed their hands to air dry, and then $1 \mathrm{~mL}$ of the $E$. coli inoculum was deposited in the center of their dominate hand. The $E$. coli was applied by rubbing hands together for $30 \mathrm{sec}$, and then hands were allowed to air dry for $30 \mathrm{sec}$. To enumerate bacteria on subject's hands the dominate hand was placed into a sterile stomacher bag with $20 \mathrm{~mL}$ of sterile $0.1 \%$ peptone and rinsed for 30 seconds, covering all fingers, palm, and back of the hand. Next, $1 \mathrm{~mL}$ of the peptone solution was removed from the stomacher bag, placed into $9 \mathrm{~mL}$ of sterile $0.1 \%$ peptone and serially diluted. From each serial dilution, $0.1 \mathrm{~mL}$ was spread-plated in duplicate directly onto the surface of the tryptic soy agar (TSA) plates. TSA plates were incubated at $35^{\circ} \mathrm{C}$ for $24 \mathrm{~h}$, and then dilutions with 25 - 250 colonies were counted and converted to CFU/mL.

For treatments 2 and 3, each subject washed their hands and put on sterile latex-free, powder-free gloves. The control sample was prepared by weighing 5 grams of popcorn into a weigh boat and removing approximately 2 grams of popcorn with a gloved hand. The handful that was removed and popcorn left in the bowl were placed into separate filter stomacher bags, each with $20 \mathrm{~mL}$ of sterile $0.1 \%$ peptone solution. The popcorn and peptone were mixed for $30 \mathrm{sec}$ in the bag. Then $1 \mathrm{~mL}$ samples of the liquid from the bags were taken in duplicate, plated on TSA, and spread. The stomacher bags had filter dividers so that popcorn could be separated from the rinse solution. Samples were incubated and counted as described for the hand sample.

For treatments 4 and 5, inoculated hand samples were prepared by weighing $5 \mathrm{~g}$ of popcorn in a sterile weigh boat with clean hands and gloves. Subjects' hands were washed and allowed to dry and then $1 \mathrm{~mL}$ of non-pathogenic $E$. coli was placed in the palm of their dominant hand. The $E$. coli was spread onto hands as previously described. Approximately 2.5 grams of popcorn was removed from the weigh boat with each subject's inoculated dominant hand. This handful and left-over popcorn were placed into two separate filtered stomacher bags with $20 \mathrm{~mL}$ of $0.1 \%$ peptone and were mixed for 30 seconds. Serial dilutions were then prepared, plated, and spread in duplicate and plates were incubated and counted as previously described. Bacteria were counted 24 hours after plating by identifying CFUs under a black light. The CFUs from the popcorn taken and the popcorn left in the bowl were calculated.

\subsection{Statistical Analysis}

The experiment was replicated 17 times with two observations for each treatment yielding 34 total observations. Simple mean, standard deviation, minimum and maximum values were determined for treatment using the Sta- 
tistical Analysis System (SAS, 2014) [10]. Treatments of control popcorn (un-inoculated hands) taken or remaining, and treated (inoculated hands) popcorn taken and remaining were subjected to an analysis of variance, and since the treatments had a significant effect $(\mathrm{p}>0.05)$, were separated using the pdiff command of SAS (2014).

After preliminary testing to determine the amount comprising a handful of popcorn, $2.5 \mathrm{~g}$ was used as a target amount. Thus each bowl had approximately $5 \mathrm{~g}$ of popcorn placed into the test bowl. Weights of popcorn were recorded and the average, mean, median, standard deviation and range are shown in Table 1 . There was detectable transfer of bacteria from hands to popcorn taken from the bowl and to popcorn left in the bowl and the number of bacteria recovered from popcorn taken was greater than the populations recovered from popcorn left (Table 2). Of the total 136 observations involving inoculated hands, 24 had no detectable bacteria. When only observations having detectable bacteria recovered were included in the analysis, the average population of bacteria recovered from popcorn taken from the bowl was $217 \mathrm{CFU} / \mathrm{sample}$ and for popcorn left in the bowl was 60 $\mathrm{CFU} / \mathrm{sample}$. The rate of transfer from inoculated hands to popcorn was very low ( $0.2 \%$ maximum transfer) to popcorn taken and popcorn left (0.009\% maximum transfer).

Bacteria were transferred from hands to both the popcorn in the handful removed from the bowl and the popcorn left in the bowl. As expected, popcorn taken from the bowl picked up more bacteria than the leftover popcorn since the inoculated hand had more contact with the popcorn removed from the bowl. While the typical handful of popcorn was estimated to be $2.5 \mathrm{~g}$, a serving size on the nutritional labels ranged from 28 to $35 \mathrm{~g}$ for popped corn (one brand listed $83 \mathrm{~g}$ as a serving size). Therefore, consuming just one full serving for the majority of popcorn brands would require about 12 handfuls. Most bags have 2 - 4 servings; thus consuming a full bag would likely require 24 to 48 handfuls per bag. Bacteria that are in the environment can be transferred to hands and the direct contact of food with the hands can result in food contamination.

Reynolds et al. (2005) [8] reported that 1 in 4 public surfaces were highly soiled and it has been determined that bacteria (Salmonella spp.) survived 28 days on ceramic tile surfaces (Dawson et al., 2007) [11]. Barker and Bloomfield (2001) [12] reported that Salmonella Enteriditis persisted on toilet seats after infected humans had used the bathroom and that Salmonella spp. were recovered up to 50 days after inoculation onto ceramic toilet surfaces. Furthermore, these researchers reported that Salmonellae were aerosolized and transferred to other nearby surfaces after toilet flushing which showed how easily bacteria spread to other surfaces. Hands that come into contact with contaminated surfaces were found to play an important role in transmission of bacteria (Scott

Table 1. Weight (g) of sample handfuls and sample left after removing a handful of popcorn.

\begin{tabular}{cccccc}
\hline \multirow{2}{*}{ Sample } & \multicolumn{5}{c}{ Popcorn (g) } \\
\cline { 2 - 6 } & Mean & Median & Standard deviation & Minimum & Maximum \\
\hline Popcorn removed from bowl & 2.22 & 2.00 & 0.44 & 1.73 & 3.32 \\
Popcorn remaining in bowl & 2.80 & 2.99 & 0.45 & 1.70 & 3.36 \\
\hline
\end{tabular}

$\mathrm{N}=17$.

Table 2. Escherichia coli population (CFU/sample) of inoculated hands, popcorn handfuls and popcorn left in the bowl.

\begin{tabular}{|c|c|c|c|c|c|}
\hline Sample & Mean & Median & Standard deviation & Minimum & Maximum \\
\hline Inoculated hand & 501,000 & 423,000 & 418,000 & 16,500 & $1,400,000$ \\
\hline Control popcorn removed & $<10^{\mathrm{c}}$ & $<10$ & $<10$ & $<10$ & $<10$ \\
\hline Control popcorn remaining & $<10^{\mathrm{c}}$ & $<10$ & $<10$ & $<10$ & $<10$ \\
\hline Popcorn taken with inoculated hand & $185^{\mathrm{a}}$ & 91 & 352 & $<10$ & 1820 \\
\hline Popcorn remaining from inoculated hand & $48^{\mathrm{b}}$ & $<10$ & 73 & $<10$ & 415 \\
\hline \% Transfer from inoculated hand to popcorn taken & 0.0036 & & 0.025 & 0 & 0.215 \\
\hline$\%$ Transfer from inoculated hand to popcorn remaining & 0.0006 & & 0.0018 & 0 & 0.009 \\
\hline
\end{tabular}

a,b,c means for popcorn taken, remaining and control samples with the same superscript are not significantly different $(\mathrm{p}>0.05)$. $\mathrm{n}=34$. 
and Bloomfield, 1990) [13]. Transmission of disease by pathogens on human hands is a key public health concern (Chiller et al., 2001; Pittet et al., 2006; Boyce et al., 2002; Larson, 2001) [14]-[17]. Thus, sharing popcorn with others will transfer bacteria to the popcorn left in the bowl and to the handful eaten. With the large consumption of popcorn in movie theaters and other social venues, the likelihood of people eating the popcorn and having clean hands is diminished greatly. Consuming popcorn in public venues could result in "self-contamination" from touching surfaces such as doors, seats, armrests etc. and "cross-contamination" from sharing popcorn with others. While the likelihood of transferring bacteria from one person to another person is low (low transfer rate to popcorn left in the bowl), transfer to popcorn left did occur. Consumption of a bowl or bag of popcorn results in taking multiple handfuls, which would increase the contact of popcorn, left in the bag/bowl and increase the chance of cross-contamination to someone else sharing the popcorn. In this experiment, the hand inoculation levels were high and not typical for individuals using good hand hygiene. Another consideration is that fingers are often placed into the mouth and contact surfaces of the mouth during eating. Thus transfer of disease-causing agents from the oral cavity is possible. Kolenbrander et al. (2002) [18] reported that 500 - 700 types of bacterial species can be found in the mouth and since these bacteria are not normally found elsewhere in the body most are considered pathogenic. The mouth is a prime source for spreading infectious diseases (CDC, 2014) [19] and five infectious diseases are spread by oral saliva (Harrel and Molinari, 2004) [20] some of which are life-threatening (Sumi et al., 2006) [21]. Bacterial populations of saliva were approximately 1 million bacteria per $\mathrm{mL}$ (Trevino et al., 2009) [22]. These researchers also reported that oral bacteria were transferred from a bitten cracker to a dip at a rate of approximately $3 \mathrm{logs} / \mathrm{mL}$. Thus, if fingers are placed into the mouth when consuming popcorn, transfer of these bacteria to popcorn may occur. It can be assumed that most healthy adults have immune systems that can tolerate the contamination of shared popcorn. However those consuming shared popcorn that have a weakened immune system (elderly, young children, pregnant women, sick individuals, etc.) may be at higher risk of getting a foodborne illness when sharing popcorn.

\section{Acknowledgements}

Technical Contribution No. 6389 of the Clemson University Experiment Station. Partially supported by the Clemson University Creative Inquiry Program.

\section{References}

[1] Gustaitis, J. (2001) The Explosive History of Popcorn: From Maize to Microwaves, America’s Best-Loved Snack Food Has Long Been a Favorite Treat. American History, 32-36.

[2] Anaya, I., Aguirrezabal, A., Ventura, M., Comellas, L. and Agut, M. (2008) Survivability of Salmonella Cells in Popcorn after Microwave Oven and Conventional Cooking. Microbiological Research, 163, 73-79. http://dx.doi.org/10.1016/j.micres.2006.03.010

[3] Gao, Z., Tseng, C.H., Pei, Z.H. and Blaser, M.J. (2007) Molecular Analysis of Human Forearm Superficial Skin Bacterial Biota. Proceedings of the National Academies of Science, 104, 2927-2932. http://dx.doi.org/10.1073/pnas.0607077104

[4] Grice, E., Kong, H.H., Renaud, G., Young, A.C., NISC Comparative Sequencing Program, Bouffard, G.G., Blakesley, R.W., Wofsberg, T.G., Turner, M.L. and Segre, J.A. (2008) A Diversity Profile of the Human Skin Microbiota. Genome Research, 18, 1043-1050. http://dx.doi.org/10.1101/gr.075549.107

[5] Fierer, N., Hamady, M., Lauber, C.L. and Knight, R. (2008) The Influence of Sex, Handedness, and Washing on the Diversity of Hand Surface Bacteria. Proceedings of the National Academy of Science, 105, 17994-17999. http://dx.doi.org/10.1073/pnas.0807920105

[6] Jumaa, P.A. (2005) Hand Hygiene: Simple and Complex. International Journal of Infectious Diseases, 9, 3-14. http://dx.doi.org/10.1016/j.ijid.2004.05.005

[7] Judah, G., Donachie, P., Cobb, E., Schmidt, W., Holland, M. and Curtis, V. (2010) Dirty Hands: Bacteria of Faecal Origin on Commuters' Hands. Epidemiology and Infection, 138, 409-414. http://dx.doi.org/10.1017/S0950268809990641

[8] Reynolds, K.A., Watt, P.A., Boone, S.A. and Gerba, C.P. (2005) Occurrence of Bacteria and Biochemical Markers on Public Surfaces. International Journal of Environmental Health Research, 15, 225-243. http://dx.doi.org/10.1080/09603120500115298

[9] Jiang, X.J., Morgan, P. and Doyle, M. (2002) Fate of Escherichia coli O157:H7 in Manure-Amended Soil. Applied Environmental Microbiology, 68, 2605-2609. http://dx.doi.org/10.1128/AEM.68.5.2605-2609.2002 
[10] SAS (2014) Statistical Analysis System. The SAS Institute, Cary, NC.

[11] Dawson, P.L., Han, I., Cox, C. and Simmons, L. (2007) Residence Time and Food Contact Time Effects on Transfer of Salmonella Typhimurium from Tile, Wood and Carpet: Testing the Five-Second Rule. Journal of Applied Microbiology, 107, 945-953.

[12] Barker, J. and Bloomfield, S.F. (2000) Survival of Salmonella in Bathrooms and Toilets in Domestic Homes Following Salmonellosis. Journal of Applied Microbiology, 89, 137-144. http://dx.doi.org/10.1046/j.1365-2672.2000.01091.x

[13] Scott, E. and Bloomfield S.F. (1990) The Survival and Transfer of Microbial Contamination via Cloths, Hands and Utensils. Journal of Applied Bacteriology, 68, 271-278. http://dx.doi.org/10.1111/j.1365-2672.1990.tb02574.x

[14] Chiller, K., Selkin, B.A. and Murakawa, G.J. (2001) Skin Microflora and Bacterial Infections of the Skin. Journal of Investigative Dermatology Symposium Proceedings, 6, 170-174. http://dx.doi.org/10.1046/j.0022-202x.2001.00043.x

[15] Pittet, D., Allegranzi, B., Sax, H., Dharan, S., Pessoa, C.L., Donaldson, L. and Boyce, J.M. (2006) Evidence-Based Model for Hand Transmission during Patient Care and the Role of Improved Practices. Lancet Infectious Diseases, 6, 641-652. http://dx.doi.org/10.1016/S1473-3099(06)70600-4

[16] Boyce, J.M. and Pittet, D. (2001) Guideline for Hand Hygiene in Health-Care Settings. Recommendations of the Healthcare Infection Control Practices Advisory Committee and the HICPAC/SHEA/APIC/IDSA Hand Hygiene Task Force. CDC Morbidity and Mortality Weekly Report, 51, 1-45.

[17] Larson, E. (2001) Hygiene of the Skin: When Is Clean Too Clean? Emerging Infectious Diseases, 7, 225-339. http://dx.doi.org/10.3201/eid0702.010215

[18] Kolenbrander, P.E., Andersen, R.N., Blehert, D.S., Egland, P.G., Foster, J.S. and Palmer, R.J. (2002) Communication among Oral Bacteria. Microbiology and Molecular Biology Reviews, 66, 486-505. http://dx.doi.org/10.1128/MMBR.66.3.486-505.2002

[19] CDC, Centers of Disease Control. 2014. http://www.cdc.gov/flu/protect/covercough.htm

[20] Harrel, S. and Molinari, J. (2004) Aerosols and Splatter in Dentistry: A Brief Review of the Literature and Infection Control Implications. Journal of American Dentist Association, 135, 429-437. http://dx.doi.org/10.14219/jada.archive.2004.0207

[21] Sumi, Y., Miura, H., Michiwaki, Y., Nagaosa, S. and Nagaya, M. (2006) Colonization of Dental Plaque by Respiratory Pathogens in Dependent Elderly. Archives of Gerontology and Geriatrics, 44, 119-124. http://dx.doi.org/10.1016/j.archger.2006.04.004

[22] Trevino, J., Ballieu, B., Yost, R., Danna, S., Harris, G., Dejonckheere, J., Dimitroff, D., Philips, M., Han, I., Moore, C. and Dawson, P. (2009) Effect of Biting before Dipping (Double-Dipping) Chips on the Bacterial Population of the Dipping Solution. Journal of Food Safety, 29, 37-48. http://dx.doi.org/10.1111/j.1745-4565.2008.00137.x 